\title{
PROFESSIONAL STATUS OF MEN IN NURSING
}

\author{
Tanya Paskaleva ${ }^{1}$, Biyanka Tornyova ${ }^{2}$, Dimitar Shopov ${ }^{3}$ \\ 1) Department of Healthcare, Branch of Haskovo, Trakia University \\ 2) Department of Healthcare Management, Faculty of Public Health, Medical \\ University - Plovdiv \\ 3) Department of Social Medicine and Public Health, Faculty of Public Health, \\ Medical University - Plovdiv, Bulgaria.
}

\section{ABSTRACT:}

Introduction: The modern image of the profession of the "nurse" largely depends on public opinion and attitude. The new era imposes a new concept and a new vision for this profession that is not subject to gender stereotypes and prejudices.

Objective: To investigate and analyze the public viewpoint and attitude towards men who practice the nursing profession and to inspect the motivation and professional satisfaction of men practising the profession.

Materials and methods: An anonymous survey was conducted among two groups of respondents: 112 people from different age groups and 25 male trainees and practitioners of the nursing profession. The study was conducted within the period from February to March 2019. The collected primary information was introduced and processed with the statistical package SPSS Statistics 16.0 .

Results: The analysis of the data from the students' admission procedure in two universities for five consecutive years shows the insufficient interest of men in the nursing profession. The main reasons are: firstly, the name of the profession $-47,3 \%$; the lowest payment comes second $-42,9 \%$ and thirdly, the stereotypes and the feminist attitude of the society to this profession $-9,8 \%$.

Conclusion: From the analysis of the literary sources, it is clear that men have a long and significant connection with the provision of healthcare, but historically this is poorly documented. Over time this phenomenon underwent its metamorphosis under the influence of various factors. It is the time, when a decent place for men and women in the same-sex female nature of the nursing profession is assigned.

Keywords: professional status, men, nurses

\section{INTRODUCTION:}

The professional experience of men in the nursing profession is a topic that is poorly documented and largely insufficiently known to society. The participation of men in health care for the sick and needy date back to the Middle Ages. There are two major events that play a key role in the evolution of modern nursing and the inclusion of men in the care of the sick - Christianity and wars. During military actions, men were involved in the care of the sick and the wounded, driven by the desire to help and save the lives of their fellows $[1,2]$.

At the beginning of the 20th century, men that were trained in the nursing profession were not a common phenomenon for the majority of Medical Schools. This tradition continued in the 1930 s and as a result of the and widespread discrimination, men accounted for less than $1 \%$ of the total number of nurses in the United States. They were not allowed to study in Nursing Colleges. It was the year 1982 when a breakthrough happened, the US Supreme Court discontinued this discriminatory practice and condemned the policy of receiving nurses based on the same sex and violating a constitutional article on gender equality $[3,4]$. The strong need to influence the society in terms of general perception of men's presence in the nursing profession was the main motive for the establishment of the National Male Nurses Association (NMNA) (1971), which was renamed ten years later at the American Assembly for Men Nursing - AAMN (1981) [4].

The end of the discriminatory practice and the celebration of the changes emerged in the 1980s and 1990s. This resulted in increased interest and an upward trend in the presence of more and more men in this humane profession. Despite the changes in time, nursing is so associated with women that modern nursing schools undertake various promotional campaigns in their attempts to attract male students [5].

The situation is changing significantly in countries like England, men in the nursing profession account to about $10 \%$, in Canada they are $6,4 \%$ of the nurses and $9 \%$ in the United States. A project, aimed at increasing the number of male nursing practitioners up to $20 \%$, is underway $[6,7,8]$.

In Bulgaria, the training of men in the nursing profession started for the first time quite late - in the 1990s. 
For this nearly 30-year long period, there is a lack of accurate information about the total number of graduates.

The number of registered, by the Bulgarian Association of Healthcare Professionals (BAPZG), is about 50. At present, over 23000 nurses work in Bulgaria, and their number has reached the critical minimum for the last few years [9]. In this regard, the data convincingly suggests that men are much less than $1 \%$ in the nursing profession. In our country, despite the growing shortage of nurses, there are no programs and effective promotional campaigns to promote men to this profession. The analysis of documents, throughout the period in which men were trained in the nursing profession, shows that quite a lot of them have given up still in the training stage. What are the probable reasons we can only guess: insufficient motivation, random choice of the profession, low pay, doubts about difficulties in the future realization, based on stereotypes and prejudices in society to the female nature of the profession.

The objective of this study is to examine and analyze the public viewpoint and attitudes towards men practicing the nursing profession and to investigate the motivation and professional satisfaction of men practising it.

\section{MATERIALS AND METHODS:}

An anonymous survey has been conducted among two groups of respondents: 112 individuals from different age groups and 25 male trainees and practitioners of the nursing profession. The following methods were applied - direct anonymous poll and analysis of literary sources. The study was conducted within the period from February to March 2019. The principle of voluntary and anonymity is respected. The collected primary information was introduced and processed with the statistical package SPSS Statistics 16.0.

\section{RESULTS AND DISCUSSION:}

We have tracked the results of the respondents, divided into different age groups. The first group of respondents: up to 35 years old $-15,2 \%$, from 36 to 45 years $19,7 \%$, from 46 to 55 years $-18,8 \%$, from 56 to 65 years $-20,5 \%$ and over 66 years $-25,8 \%$. The average age of the first group of respondents was 53,29 (SD - 16,845) with a minimum age of 20 years and a maximum of 85 . The results indicate a certain female prevalence $(55,4 \%)$, unlike males $(44,6 \%)$. The majority of the respondents live in the city $-82,1 \%$ and $17,9 \%$ in the villages. By level of education, more than $1 / 2$ of the respondents have secondary education $-51,8 \%$, followed by those with a higher level of education $-29,5 \%$ and only $17,9 \%$ have basic education.

The other group of respondents consisted of 25 men - 5 trainees and 20 practitioners of the nursing profession in the cities of Plovdiv, Pleven, Haskovo and Dimitrovgrad. Predominant are the respondents in the age, group for up to 35 years $-86,7 \%$, followed by people within 36 to 45 years $-13,3 \%$.

In recent years, the traditional feminist model of the nursing profession has gradually begun to change, but the number of men qualified and practising this profession in our country is still small. The wide nursing deficit, the good European and worldwide experience of successful men's careers in this profession are prerequisites for the promotion of both genders.

Table 1 summarizes data from the students' admission campaign for the last five years at two universities in our country - the Medical University - Plovdiv and the Thracian University - Stara Zagora. The annual admission or quota for men in the nursing major is $10 \%$ of the total number for the speciality, which differs in the various universities according to the requested state order and according to the capacity.

Table 1. Students' admission for the "nurse" major - men

\begin{tabular}{|l|c|c|c|c|c|c|c|c|c|c|c|c|c|c|c|c|c|c|c|c|c|c|c|c|c|}
\hline Year & \multicolumn{9}{|c|}{$\mathbf{2 0 1 4}$} & \multicolumn{4}{|c|}{$\mathbf{2 0 1 5}$} & \multicolumn{4}{|c|}{$\mathbf{2 0 1 6}$} & \multicolumn{3}{|c|}{$\mathbf{2 0 1 8}$} \\
\hline Desire & 1 & 2 & 3 & $>$ & & 1 & 2 & 3 & $>$ & & 1 & 2 & 3 & $>$ & & 1 & 2 & 3 & $>$ & & 1 & 2 & 3 & $>$ & \\
\hline MU Plovdiv & 1 & - & - & - & $\mathbf{1}$ & 3 & 2 & - & - & $\mathbf{5}$ & - & - & - & - & $\mathbf{0}$ & - & - & - & - & $\mathbf{0}$ & 2 & - & - & - & $\mathbf{2}$ \\
\hline TrU - MF & 2 & - & 2 & 3 & $\mathbf{7}$ & 5 & 3 & - & 8 & $\mathbf{1 5}$ & 1 & 3 & 2 & 4 & $\mathbf{1 0}$ & - & 2 & 3 & 1 & $\mathbf{6}$ & 1 & 3 & 3 & - & $\mathbf{7}$ \\
\hline TrU - FH & 2 & - & 1 & - & $\mathbf{3}$ & 2 & 1 & - & - & $\mathbf{3}$ & 1 & - & - & 1 & $\mathbf{2}$ & 2 & - & 1 & - & $\mathbf{3}$ & - & - & - & - & $\mathbf{0}$ \\
\hline
\end{tabular}

These data are indicative of the weak interest of men in the nursing profession. Almost none of the abovementioned years have achieved a maximum admission for men in this specialty. 
Fig. 1. Causes of men's inadequate interest in the nursing profession

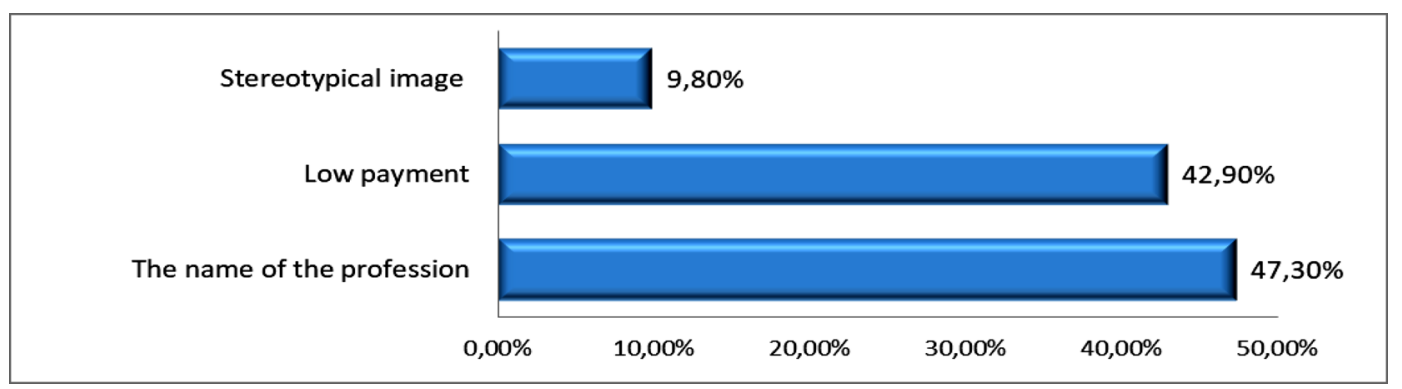

According to the respondents, the main reasons for the insufficient interest of men in the nursing profession is the name of the profession, at first place - 47,3\%; secondly the low pay - 42,9\% and thirdly - the stereotypes and feminist attitude of the society to this profession $9,8 \%$ (fig.1). The results, reflecting the position of male and female practitioners, coincide hierarchically with the mentioned above.

The viewpoint and the opinion of $56,3 \%$ of the respondents iarethat the name of the nursing profession influences the choice of men as well. The second part of the name "nurse" has an unequivocal association with women. On the opposite side, $30,4 \%$ and $13,4 \%$ have no exact position on the issue. The results of the survey show that with the increase of education, the respondents believe that the name of the nursing profession influences the choice of men $\mathrm{P}=0,025(\chi 2=14,41)$. The found correlation is moderate $\mathrm{P}=0,001(\mathrm{r}=0,312)$.

Today, in many countries, there is a separate address for both men and women. At present in Bulgaria, there does not exist an official equivalent for a man, practising this profession and "nurse" in Bulgarian language is directly connected to the female gender. In this case, a logical possibility for the patients to address the nurse is when using the family name, but often under the presumption and influenced by the media, in many cases the term a "medical brother" is used.
In recent years, the nursing profession has undergone dynamic and permanent changes. The introduced reforms are important for the professional activities of nurses and are a way of optimizing and improving healthcare quality. In this respect, the qualification and level of competence of the nurses directly correspond to the professional motivation.

The analysis of the group results of male trainees and practitioners shows that the leading motives in choosing the nursing profession are: willingness to help people $-53,3 \%$, career opportunity $-53,3 \%$ and random events $-40,0 \%$. The demographic crisis in the nursing profession and the growing shortage of nurses in our country are a reason to notice with concern that $26,6 \%$ of the respondents consider it a good opportunity to find work abroad (Figure 2).

Comparing the motives for choosing the nursing profession with other studies that the female sex dominates, the same consistency in the hierarchy of the leading motives has been established [10,11].

From the analysis of the data, it is clear that only $40 \%$ of the interviewed men are satisfied with the choice of the nursing profession and $60 \%$ have indicated "just partly" as an answer. The results show a dose of optimism, $66,6 \%$ would choose this profession again, and $33,4 \%$ have some hesitations in this direction.

Fig. 2. Men's personal motives for choosing the nursing profession

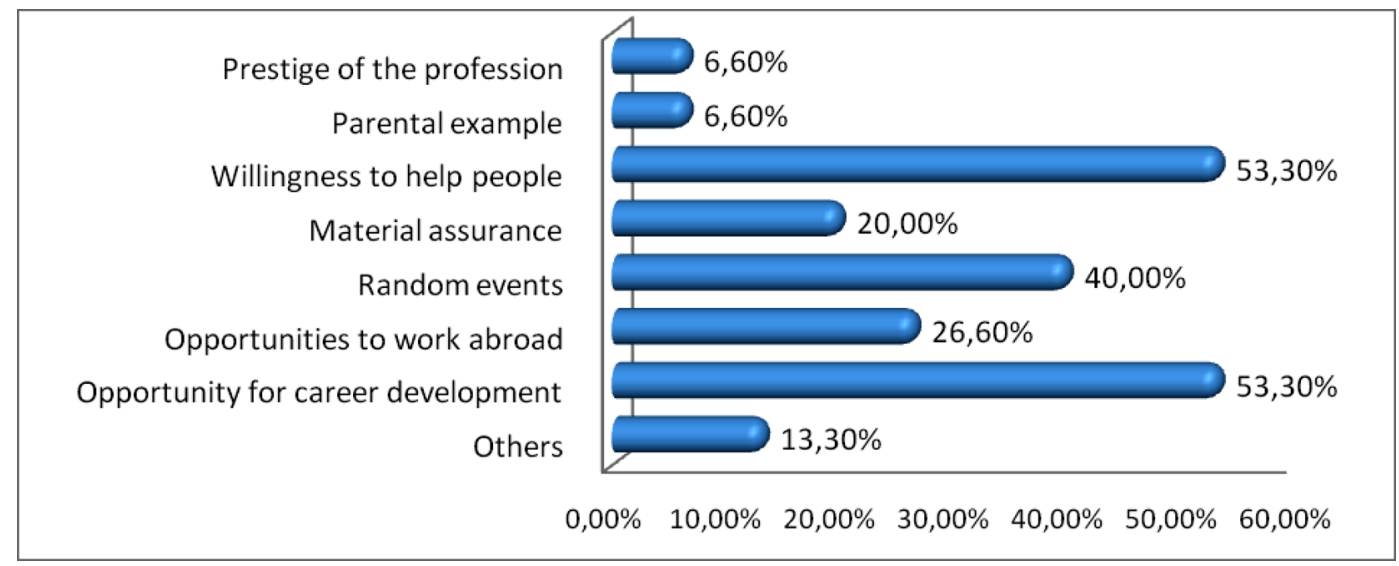

The percentages exceed 100 because there was a possibility to give more than one response. 
In this study, it is found out that $49,1 \%$ are of the opinion that male nurses are well-placed in the nursing profession. Firmly convinced that this speciality is a reserved area for women alone are 40,2\%.

In terms of "sex" index, the results show that men more often $(56,0 \%)$ have the opinion that this profession should be practiced by women $\mathrm{P}=0,004(\chi 2=11,15)$. The belief that nursing care and attendance are "female" responsibilities is a powerful barrier for men and certainly plays a significant role in the perception of the profession.

The respondents' opinion on gender selection suggests that $49,1 \%$ prefer a woman, and just as much as $49,1 \%$ say they have no preference, only $1,8 \%$ prefer a male nurse.

According to the respondents, the wards/clinics and the sectors where men would be realized most successfully are: the emergency ward $(67 \%)$, surgery ward $(65,2 \%)$, psychiatry $(56,3 \%)$, resuscitation and intensive care $(37,5 \%)$ (Figure 3$)$. The questioned believe that the healthcare sectors that suit them best are the emergency ward $-56,0 \%, P=0,027(\chi 2=4,91)$ and psychiatry ward $44,0 \%, \mathrm{P}=0,019(\chi 2=5,51)$. The results show that as education increases, the respondents believe that men are suitable for intensive reanimation and intensive therapy $\mathrm{P}=0,005\left(\chi^{2}=12,77\right)$. The established correlation is moderate $\mathrm{P}=0,001(\mathrm{r}=0,340)$. These answers are logical, because the work of these wards requires more physical strength and endurance with which men would be helpful [12].

The study shows that with the age the respondents' belief that men would best perform in the sectors: resuscitation and intensive care $\mathrm{P}=0,011(\chi 2=13,16)$, the correlation dependence is moderate $\mathrm{P}=0,001(\mathrm{r}=-0,318)$; emergency ward $\mathrm{P}=0,003(\chi 2=15,76)$ - moderate correlation dependence $\mathrm{P}=0,001(\mathrm{r}=-0,328)$ and psychiatry $\mathrm{P}=0,001(\chi 2=19,69)$, the correlation dependence is moderate $\mathrm{P}=0,001(\mathrm{r}=-0,370)$.

Fig. 3. Healthcare sectors with opportunities for a successful realization of men

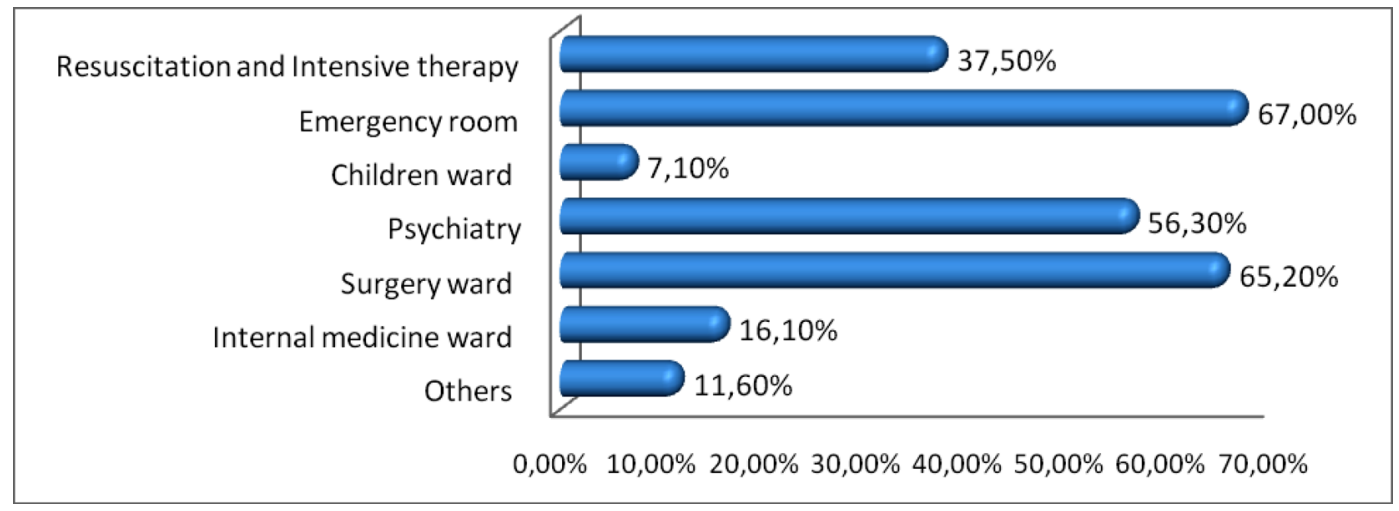

Public opinion and attitudes are extremely important for building the overall image of the nursing profession. In modern times, there is a new concept and a new vision for this profession imposed that is not subject to gender stereotypes and prejudices. The potential and qualities that are part of the male nature affirm men as a useful, effective and significant figure in the healthcare field.

More than 1/2 (62,5\%) of the respondents are convinced that men can perform well and have opportunities for professional success. In this direction, there are few examples of the European and world practice of good professional realization, including the teaching development of men in the nursing profession. From the analysis of "place of residence" data, it is clear that $67,4 \%$ of urban residents support the view that men have career prospects in the nursing profession $\mathrm{P}=0,047(\chi 2=6,13)$, compared with residents living in the villages $40,0 \%$. In rural areas, there are mainly elderly and old people, who are mostly conservative and therefore adhere to the traditional model of this profession.

\section{CONCLUSIONS:}

This study has found out:

- Insufficient interest of men in the nursing profes- sion. The main reasons are: firstly, the name of the profession $-47,3 \%$, secondly the low pay $-42,9 \%$ and thirdly - the stereotypes and feminist attitudes of the society to this profession $-9,8 \%$.

- Leading reasons for male trainees and practitioners to choose the nursing profession are: willingness to help people $-53,3 \%$, career opportunities $-53,3 \%$ and random events $-40,0 \%$.

- Only $40 \%$ are satisfied with choosing the nursing profession.

- The public model, based on prejudice on the subject under consideration, is related to gender and age: According to $56,0 \%$ of men, this profession should be practiced only by women. As age increases, the respondents' belief that men would be good is diminishing.

- $49,1 \%$ are of the opinion that the nursing profession has a decent place for men.

- The healthcare sectors that provide a career opportunity for men are: Emergency ward $(67,0 \%)$, Surgery ward $(65,2 \%)$, Psychiatry $(56,3 \%)$ and Resuscitation and Intensive Care $(37,5 \%)$.

- The point of view and the opinion of $62,2 \%$ of the survey participants is that men can perform well and have the potential for professional success. 
It is clear from the analysis of literary sources that men have a long and significant link in the provision of healthcare, but historically this is poorly documented. Over time this phenomenon underwent its metamorphosis under the influence of various factors, for the time to come when a decent place for men and women in the same-sex female nature of the nursing profession is assigned. This requires building and maintaining a positive public image that will help inform, educate, direct and motivate young people even in their school years to this profession.

\section{REFERENCES:}

1. Mackintosh C. A historical study of men in nursing. $J$ Adv Nurs. 1997; 26(2):232-236. [PubMed] [Crossref]

2. Evans J, Men Nurses: A Historical and Feminist Perspective. J Adv Nurs. 2004 Aug;47(3):321-8. [PubMed] [Crossref]

3. Harding T, Men an invisible force in nursing history. Nursing Review, October 2012, 28-29.

4. American Association for Men in Nursing (AAMN). [Internet]

5. Oregon Center for Nursing. [nternet]

6. 2010 Workforce Profile of Registered Nurses in Canada. Canadian
Nurses Association, 2012. [Internet] 7. Landivar, Liana Christin., "Men in Nursing Occupations", American Community Survey Highlight Report, 2013.

8. Williams R, Why are there so few male nurses? [online] the Guardian. 2017. [Internet]

9. Bulgarian Association of Healthcare Professionals (BAPZG), [in Bulgarian] [Internet]

10. Dragusheva S, Petlleshkova P, Kasnakova P, Mavrov M. The independent actions of trainee nurses during the pre-graduation traineeship. Trakia Journal of sciences. 2018
Sep;16(1):229-234.

11. Dragusheva S, Tornyova B, Bakova D, Petleshkova P, Nasteva L, Duran N. Students' reasons for choosing the profession of 'Registered Nurse'. Knowledge-Int J. (Skopje. Online). 2018 Mar;22(5):1379-1383. [nternet]

12. Kumpula E, Ekstrand P. Men and masculinities in forensic psychiatric care: an interview study concerning male nurses' experiences of working with male caregivers and male patients. Issues Ment Health Nurs. 2009 Sep;30(9):538-46.

[Crossref]

Please cite this article as: Paskaleva T, Tornyova B, Shopov D. Professional status of men in nursing. J of IMAB. 2020 Jan-Mar;26(1):3029-3033. DOI: https://doi.org/10.5272/jimab.2020261.3029

Received: 27/01/2020; Published online: 30/03/2020

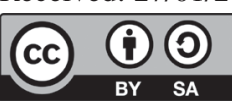

Address for correspondence:

Tanya Paskaleva

Department of Healthcare, Branch of Haskovo, Trakia University, Stara Zagora, 48, "Saedinenie" blvd., Haskovo, Bulgaria,

E-mail: paskaleva666@abv.bg 